Check for updates

Cite this: Mater. Adv., 2021, 2, 3677

Received 22nd December 2020, Accepted 6th April 2021

DOI: 10.1039/d0ma01005g

rsc.li/materials-advances

\title{
Highly efficient, ultralow turn-on voltage red and white organic light-emitting devices based on a novel exciplex host
}

\author{
Jian Song, ${ }^{a}$ Fujun Zhang, ${ }^{a}$ Liping Yang, ${ }^{a}$ Keming Chen, ${ }^{a}$ Asu Li ${ }^{a}$ Ren Sheng, ${ }^{b}$ \\ Yu Duan (iD) and Ping Chen (D) *ab
}

\begin{abstract}
The exciplex forming co-host is one of the most promising candidates for developing high-performance organic light-emitting devices (OLEDs) that can implement an internal quantum efficiency of $100 \%$. In this work, a novel exciplex co-host system by employing $\mathrm{N}$-([1,1'-biphenyl]-2-yl)- $\mathrm{N}$ - $(9,9$-dimethyl- $9 \mathrm{H}$ fluoren-2-yl)-9,9'-spirobi[fluoren]-4-amine (FSF4A) and 2,4,6-tris[3-(diphenylphosphinyl)phenyl]-1,3,5triazine (PO-T2T) is applied to design simplified red and white OLEDs with low turn-on voltage and high efficiency. A high performance red phosphorescent organic light-emitting diode (PhOLED) is achieved by employing an exciplex co-host in a low guest doping level of $3 \%$, showing the best performance with a maximum power efficiency of $38.5 \mathrm{Im} \mathrm{W}^{-1}$, a maximum external quantum efficiency of $17.3 \%$, and an ultralow turn-on voltage of $1.95 \mathrm{~V}$, respectively. Based on the red device, the ultra-thin FlrPic layer is inserted to achieve high performance white OLEDs, exhibiting a low turn-on voltage of $2.2 \mathrm{~V}$ with a maximum power efficiency of $34.1 \mathrm{~lm} \mathrm{~W}^{-1}$, and the Commission Internationale de'IEclairage (CIE) coordinate $(0.33,0.33)$ at $1000 \mathrm{~cd} \mathrm{~m}^{-2}$. These superior properties can be attributed to reduced barriers and the effective energy transfer by employing an exciplex co-host.
\end{abstract}

\section{Introduction}

Phosphorescent organic light-emitting diodes (PhOLEDs) have attracted great attention due to their extensive application prospects in the field of solid-state lighting and flat-panel displays with the theoretical value of $100 \%$ exciton utilization by harvesting both singlet and triplet excitons for electroluminescence (EL). ${ }^{1-4}$ In general, to improve the device efficiency and stability, host-guest technology is a superior method for designing high performance phosphorescent devices. ${ }^{5,6}$ The host materials usually need to have appropriate highest occupied molecular orbital (HOMO) and lowest unoccupied molecular orbital (LUMO) levels to facilitate balanced charge injection and transportation capabilities, as well as high triplet energy levels (T1) to ensure effective energy transfer and confine excitons in the phosphorescent guest. ${ }^{7-11}$ However, there are still huge challenges to achieve PhOLEDs with low driving voltage and low energy consumption. ${ }^{12,13}$ In order to meet the needs of high-quality red and white OLEDs, it is essential to design an advantageous emission layer structure, which can

\footnotetext{
${ }^{a}$ State Key Laboratory on Integrated Optoelectronics, College of Electronic Science and Engineering, Jilin University, Changchun, China. E-mail: pingchen@jlu.edu.cn

${ }^{b}$ Institute of Science and Technology for Opto-Electronic Information,

Yantai University, Yantai 264005, China
}

achieve high exciton utilization for both singlet and triplet, as well as effective charge injection and transportation at low voltage. $^{14}$

Recently, the co-host of an exciplex formed by an acceptor and a donor, instead of traditional hole or electron type single hosts, have been regarded as a promising candidate for using as a host on phosphorescent OLEDs due to its good charge balance and exciton utilization. ${ }^{15-20}$ Furthermore, it has been demonstrated that an exciplex host with small singlet-triplet energy difference $\left(\Delta E_{\mathrm{st}}\right)$ can notably reduce the turn-on voltage and improve the power efficiency (PE) and external quantum efficiency (EQE) of the PhOLEDs. ${ }^{21-23}$ In general, exciplex systems are found to have a thermally activated delayed fluorescence (TADF) effect through reverse intersystem crossing (RISC), triplet excitons can be upconverted to single excitons due to intrinsically smaller $\Delta E_{\text {st }}$ values. ${ }^{24,25}$ It is found that the exciplex co-host is more beneficial to facilitate effective Förster energy transfer, which can further improve device efficiency. ${ }^{26,27}$ Many exciplex co-host systems have been reported to demonstrate high efficiency of red and white phosphorescent OLEDs with the development of an exciplex co-host. Sheng et al. adopted an exciplex co-host to achieve red phosphorescent OLEDs with a maximum power efficiency of $35.3 \mathrm{~lm} \mathrm{~W}^{-1}$ and external quantum efficiency of $19.8 \%{ }^{28} \mathrm{Xu}$ et al. reported a red phosphorescent OLED through an exciplex co-host system with a 
maximum power efficiency of $31.8 \mathrm{~lm} \mathrm{~W}^{-1}$ and turn-on voltage of $2.24 \mathrm{~V}^{29}$ Yao et al. realized a red phosphorescent device with a maximum power efficiency of $36.9 \mathrm{~lm} \mathrm{~W}^{-1}$ and external quantum efficiency of $15.5 \% .^{30}$ However, despite the remarkable progress in the use of exciplex co-hosts in OLEDs, it is still a great challenge to precisely predict the likelihood of electron hole pairs inducing exciplex emission and achieving ultra-low turn-on voltage PhOLEDs.

In this work, a novel exciplex system is fabricated by employing a new hole transport material of $N-\left(\left[1,1^{\prime}\right.\right.$-biphenyl $\left.]-2-y l\right)-N$ (9,9-dimethyl-9H-fluoren-2-yl)-9,9'-spirobi[fluoren]-4-amine (FSF4A) and electron transport material of 2,4,6-tris[3-(diphenylphosphinyl)phenyl]-1,3,5-triazine (PO-T2T), the yellow exciplex emission can be observed in both photoluminescence (PL) and electroluminescence (EL). Compared with common mixed-host devices, the red PhOLED based on an exciplex co-host demonstrates an ultralow turn-on voltage of $1.95 \mathrm{~V}$ and a maximum power efficiency of $38.5 \mathrm{~lm} \mathrm{~W}^{-1}$ with an external quantum efficiency of $17.3 \%$. Moreover, its turn-on voltage is almost the same as the lowest turn-on voltage achieved by the red OLED based on an exciplex co-host. ${ }^{31}$ By further inserting a blue ultrathin layer, the white OLED achieves an ultralow turn-on voltage of $2.2 \mathrm{~V}$ and a maximum power efficiency of $34.1 \mathrm{~lm} \mathrm{~W}^{-1}$ with an external quantum efficiency of $12.4 \%$, and the turn-on voltage is almost one of the lowest compared to previous ref. 32 and 33 . Furthermore, the Commission Internationale de'IEclairage (CIE) coordinates are $(0.33,0.33)$ at $1000 \mathrm{~cd} \mathrm{~m}^{-2}$, and the CIE coordinate variation is only $(0.026,0.003)$ over a large luminance range, which is better among the WOLEDs of exciplex co-hosts. It is found that the high performances of PhOLEDs are mainly attributed to balanced charge transport and appropriate energy transfer channels from an exciplex co-host to the dopant. This work may provide valuable clues for the rational design of exciplex systems, as well as their application as co-host materials in PhOLEDs with high efficiency and ultralow turn-on voltage.

\section{Experimental section}

\subsection{Materials}

FSF4A was purchased from Shenzhen PURI Materials Technologies Co., Ltd Ir(MDQ) ${ }_{2}$ acac and FIrPic were purchased from Luminescence Technology Corp. $\mathrm{MoO}_{3}$, TPBi, MCP, Liq, and PO-T2T were purchased from Xi'an Polymer Light Technology Corp.

For the basic parameters of FSF4A: $\mathrm{S}_{1}$ is $3.0 \mathrm{eV}, \mathrm{T}_{1}$ is $2.6 \mathrm{eV}$, HOMO is $5.3 \mathrm{eV}$, LUMO is $2.1 \mathrm{eV}$, and the absorption peak positions are $310 \mathrm{~nm}$ and $340 \mathrm{~nm}$.

\subsection{Device fabrication and characterization}

The OLED were grown on pre-patterned ITO coated glass (20 $\Omega$ per square). Before depositing into the evaporation system, the ITO substrates were cleaned with acetone, ethyl alcohol, and deionized water using an ultrasonic cleaning machine for $20 \mathrm{~min}$. All the devices were deposited sequentially under a fine vacuum of $8 \times 10^{-5} \mathrm{~Pa}$. The organic transport materials were grown at a rate of 0.8-1.5 $\AA \mathrm{s}^{-1}$, while organic dopants $\operatorname{Ir}(\mathrm{MDQ})_{2}$ acac and FIrPic were deposited at a rate of $0.01-0.1 \AA^{-1}$, the FIrPic ultra-thin layer of $0.2 \mathrm{~nm}$ is deposited at a rate of $0.05 \AA^{-1}$ for $40 \mathrm{~s}$, Liq and $\mathrm{MoO}_{3}$ were deposited at a rate of $0.15-0.3 \AA \mathrm{s}^{-1}$, and $\mathrm{Al}$ was deposited at a rate of $3 \AA \mathrm{s}^{-1}$.

The photoluminescence (PL) spectra were acquired by an RF-5301PC fluorescence spectrophotometer. The transient PL decay curves were recorded using an IHR320 spectrometer. The CIE coordinates, luminance and electroluminescent (EL) spectra were recorded using a PR655 spectra-scan photometer simultaneously. The CE, PE, and EQE were measured using a programmable Keithley 2400 source-meter and an absolute external quantum efficiency measurement system. All devices were characterized at room temperature without encapsulation.

\section{Results and discussion}

Recently, organic light-emitting diodes using exciplex as the host have been extensively researched compared with traditional host devices due to their excellent EL performance. Fig. 1 shows the energy level diagrams and chemical structures of the materials used in this work. From the orbital energy level diagram (Fig. 1a), the difference between the LUMO of the donor of FSF4A and the acceptor of PO-T2T is $1.1 \mathrm{eV}$, which can effectively restrict the electrons from PO-T2T to FSF4A; meanwhile, their HOMO difference is $1.8 \mathrm{eV}$, which can also obviously block the hole from FSF4A to PO-T2T. Therefore, we infer that such a large energy level difference may produce an exciplex system. ${ }^{34}$

The photoluminescence (PL) spectra of FSF4A, PO-T2T (solution), TPBi, FSF4A:PO-T2T (molar ratio of $1: 1$ ) and FSF4A:TPBi (molar ratio of $1: 1$ ) are depicted in Fig. 2(a and b). As can been seen, the PL emission spectra (films measured at $300 \mathrm{~K}$ ) of FSF4A, PO-T2T (solution) and FSF4A : PO-T2T mixed film (1:1, molar ratio) are completely different, and the PL emission peak position of the FSF4A:PO-T2T film is $549 \mathrm{~nm}$, which is obviously red-shifted relative to those of the pure FSF4A or PO-T2T (i.e., $407 \mathrm{~nm}$ for FSF4A and $419 \mathrm{~nm}$ for PO-T2T). The PL spectrum of the FSF4A:PO-T2T mixed film also exhibits a full width at half maximum of $103 \mathrm{~nm}$, and it is highly shifted to the long wavelength region due to its intermolecular charge transfer (CT) characteristics. ${ }^{35}$ The exciplex photon energy of FSF4A:PO-T2T can be estimated to be $2.25 \mathrm{eV}$
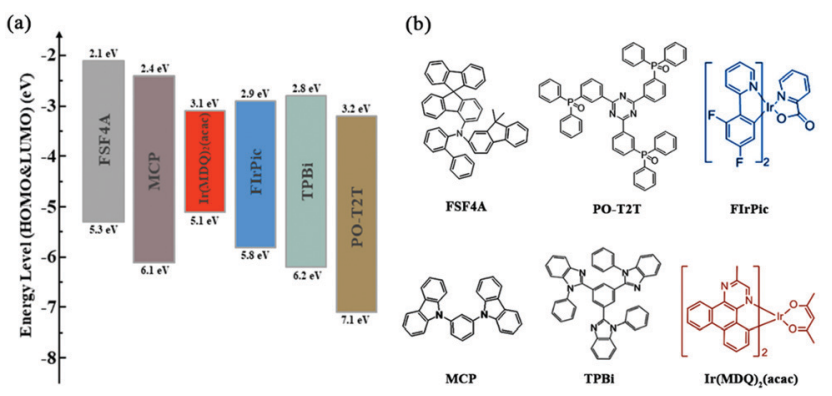

Fig. 1 The organic materials used in this work (a) energy level diagram and (b) chemical structures. 

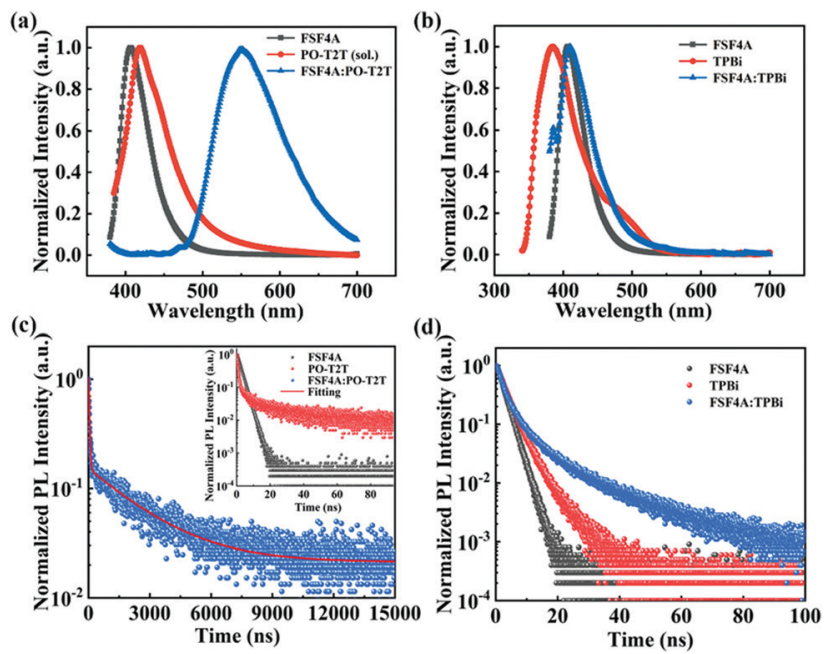

Fig. 2 Normalized PL spectra of (a) FSF4A, PO-T2T solution, and FSF4A PO-T2T (1:1) co-deposited film; (b) FSF4A, TPBi, and FSF4A:TPBi (1:1) co-deposited film (all films are $70 \mathrm{~nm}$ thick and measured at $300 \mathrm{~K}$ ). Transient decay curves of (c) FSF4A, PO-T2T, and FSF4A: PO-T2T (1:1) co-deposited film; (d) FSF4A, TPBi, and FSF4A:TPBi (1:1) co-deposited film (all films are $50 \mathrm{~nm}$ thick and measured at $300 \mathrm{~K}$ ).

by the emission peak of the mixed film. The value is quite close to the difference $(2.1 \mathrm{eV})$ between the HOMO of FSF4A (donor) and the LUMO of PO-T2T (acceptor). The results indicate that an exciplex is formed between the FSF4A molecule and the PO-T2T molecule under photo excitation, and the FSF4A:PO-T2T mixed film generates a pure CT exciplex emission. The PL emission spectrum of the peak position of the FSF4A: TPBi film (1:1, molar ratio) at $409 \mathrm{~nm}$ and $385 \mathrm{~nm}$ is depicted in Fig. $2 \mathrm{~b}$, which is quite similar to those of pure FSF4A $(407 \mathrm{~nm})$ and TPBi $(385 \mathrm{~nm})$ films. Thus, we infer that the mixed film of FSF4A:TPBi cannot form exciplex emission. The formation process of the exciplex can be described as the following eqn $(1)^{36}$

$$
\begin{gathered}
\text { Donor }(\mathrm{D})+\operatorname{Acceptor}(\mathrm{A})+h \nu \rightarrow \mathrm{D}^{*}+\mathrm{A} \text { or } \mathrm{D}+\mathrm{A}^{*} \\
\rightarrow\left(\mathrm{D}^{\delta+} \mathrm{A}^{\delta-}\right)^{*} \rightarrow h \nu_{\text {exciplex }}+\mathrm{D}+\mathrm{A}
\end{gathered}
$$

In order to further confirm the formation of exciplex in the FSF4A:PO-T2T mixed film and the absence of exciplex in the FSF4A:TPBi mixed film, the transient decay PL curves are measured at $300 \mathrm{~K}$. The transient decay curves of FSF4A, PO-T2T and FSF4A:PO-T2T mixed films are depicted in Fig. 2c. The FSF4A film shows transient PL decay time components of $2.65 \mathrm{~ns}$, and that of the PO-T2T film exhibits two decay components with times of $0.85 \mathrm{~ns}$ and $18.92 \mathrm{~ns}$. Obviously different from the films of donor and acceptor molecules, the mixed film of FSF4A:PO-T2T contains a long-lived delayed component with a decay time of $2.45 \mu$ s and a short decay time of $37.53 \mathrm{~ns}$. Furthermore, the short decay time of $37.53 \mathrm{~ns}$ in the mixed film can be attributed to the prompt fluorescence of the FSF4A:PO-T2T exciplex, rather than the separate FSF4A and PO-T2T. The long decay time of 2.45 us can be attributed to the delayed fluorescence of the FSF4A:POT2T exciplex. ${ }^{37}$ Meanwhile, the fitting formula for the tested data of the exciplex is as follows:

$$
I(t)=A_{1} \exp \left(-t / \tau_{1}\right)+A_{2} \exp \left(-t / \tau_{2}\right)
$$

where $A_{1}$ and $A_{2}$ are the constants fitted according to the data of the photoluminescence lifetime test, while $\tau_{1}$ and $\tau_{2}$ are the fitted prompt fluorescence and delayed fluorescence components respectively. The high RISC process from triplet to singlet is attributed to the small $\Delta E_{\mathrm{st}}$. The $\Delta E_{\mathrm{st}}$ value can be obtained from the following formula:

$$
\Delta E_{\mathrm{ST}}=R T \ln \left(K_{\mathrm{eq}} / 3\right)
$$

where $R$ is the ideal gas constant, $T$ is the thermodynamic temperature, $K_{\mathrm{eq}}$ is the ratio of the intersystem crossing process $\left(k_{\mathrm{ISC}}\right)$ and reverse intersystem crossing $\left(k_{\mathrm{RISC}}\right), k_{\mathrm{ISC}}$ and $k_{\mathrm{RISC}}$ can be obtained by the following formulae: ${ }^{38}$

$$
\begin{gathered}
K_{\mathrm{P}}=\frac{1}{\tau_{\mathrm{PF}}} \\
K_{\mathrm{D}}=\frac{1}{\tau_{\mathrm{DF}}} \\
K_{\mathrm{ISC}}=K_{\mathrm{p}} \times\left(1-\Phi_{\mathrm{PF}}\right) \\
K_{\mathrm{RISC}}=\frac{K_{\mathrm{D}} K_{\mathrm{F}} \Phi_{\mathrm{DF}}}{K_{\mathrm{ISC}} \Phi_{\mathrm{PF}}}
\end{gathered}
$$

where $\Phi_{\mathrm{PF}}$ and $\Phi_{\mathrm{DF}}$ are the photoluminescence quantum efficiency of PF and DF respectively, $\tau_{\mathrm{PF}}$ and $\tau_{\mathrm{DF}}$ can be revealed by fitting the decay curve in the time-resolved PL spectrum. We obtained $k_{\text {ISC }}$ of $2.57 \times 10^{7} \mathrm{~S}^{-1}$ and $k_{\mathrm{RISC}}$ of $3.42 \times 10^{6} \mathrm{~S}^{-1}$, and calculated that the singlet-triplet energy difference of the exciplex is $0.5 \mathrm{kcal} \mathrm{mol}^{-1}$ $(0.022 \mathrm{eV})$. The photoluminescence quantum yield $\left(\eta_{\mathrm{PL}}\right)$ is $31 \%$ $(5: 5)$. Thus, the exciplex system can be realized by effectively converting the triplet CT into singlet CT through the reverse intersystem crossing (RISC). Fig. $2 \mathrm{~d}$ shows the transient decay curve of the mixed film FSF4A:TPBi, which has a significantly shorter exciton lifetime compared to FSF4A:PO-T2T. These results further support the formation of FSF4A:PO-T2T exciplex emission, while FSF4A:TPBi cannot form exciplex emission.

To investigate the EL characteristics of the FSF4A:PO-T2T exciplex, an OLED is fabricated with the exciplex as the emission layer (EML) by the structure of ITO/ $\mathrm{MoO}_{3}(2 \mathrm{~nm}) / \mathrm{FSF} 4 \mathrm{~A}(45 \mathrm{~nm}) /$ FSF4A:PO-T2T $(20 \mathrm{~nm}) / \mathrm{PO}-\mathrm{T} 2 \mathrm{~T}(35 \mathrm{~nm}) / \mathrm{Liq}(1 \mathrm{~nm}) / \mathrm{Al}(100 \mathrm{~nm})$. The ratio of FSF4A:PO-T2T is $3: 7,5: 5$, and $7: 3$, respectively. As exhibited in Fig. $3(\mathrm{a}-\mathrm{c})$, the device based on the exciplex emission layer with a mixing ratio of $5: 5$ can achieve the maximum luminance $\left(L_{\max }\right)$ of $18513 \mathrm{~cd} \mathrm{~m}^{-2}$, the maximum $\mathrm{CE}$ of $16.4 \mathrm{~cd} \mathrm{~A}^{-1}$ and the maximum PE of $17.2 \mathrm{~lm} \mathrm{~W}^{-1}$ with an ultralow turn-on voltage of $2.4 \mathrm{~V}$. Detailed characteristics are summarized in Table 1. The low turn-on voltage and high performance can be attributed to the "barrier-free" device structure, that is, holes and electrons can be injected into EML from FSF4A and PO-T2T without barrier, respectively. ${ }^{39}$ Meanwhile, the device with the FSF4A: PO-T2T mixing ratio of $5: 5$ achieves the greatest luminance and efficiency, which is due to a more balanced carrier transport. Therefore, all the OLEDs based on FSF4A:PO-T2T emitting were developed with the 

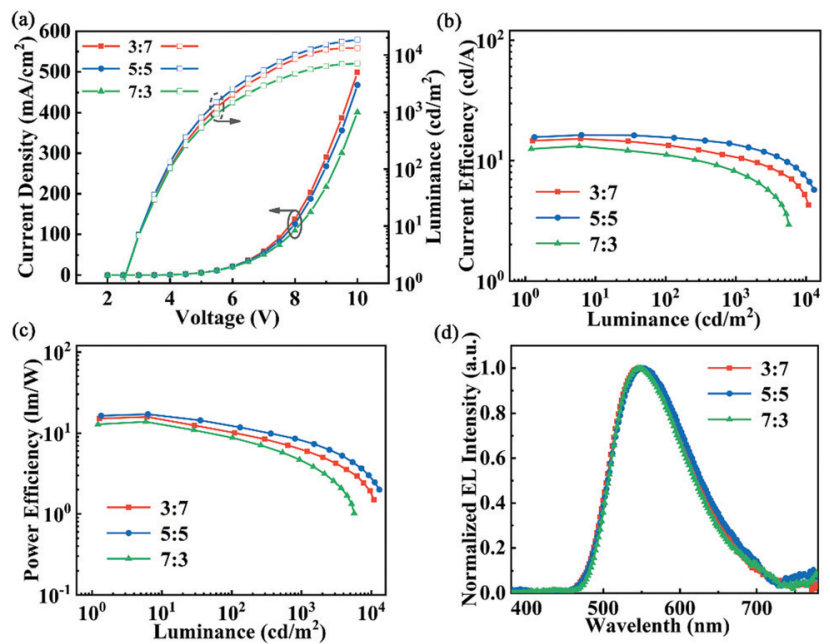

Fig. 3 (a) Current density-voltage-luminance characteristics of the device. (b) Current efficiency-luminance characteristics of the device. (c) Power efficiency-luminance characteristics of the device. (d) Normalized EL spectra of the device at $6 \mathrm{~V}$.

Table 1 Performance of OLEDs with exciplex as the emission layer

\begin{tabular}{llllllll}
\hline $\begin{array}{l}\text { Mixing } \\
\text { ratio }\end{array}$ & $\begin{array}{l}{ }^{b}{ }^{b} \\
V_{\text {on }}{ }^{a}[\mathrm{~V})\end{array}$ & $\begin{array}{l}L_{\mathrm{max}} \\
{\left[\mathrm{cd} \mathrm{m}^{-2}\right]}\end{array}$ & $\begin{array}{l}\mathrm{CE}^{c} \\
{\left[\mathrm{~cd} \mathrm{~A}^{-1}\right]}\end{array}$ & $\begin{array}{l}\mathrm{PE}^{c} \\
{\left[\mathrm{~lm} \mathrm{~W}^{-1}\right]}\end{array}$ & $\begin{array}{l}\mathrm{EQE}^{c} \\
{[\%]}\end{array}$ & $\begin{array}{l}\lambda_{\mathrm{EL}}{ }^{d} \\
{[\mathrm{~nm}]}\end{array}$ & $\begin{array}{l}\mathrm{CIE}^{e} \\
{[x, y]}\end{array}$ \\
\hline $3: 7$ & 2.40 & 13192 & 15.2 & 15.9 & 5.87 & 550 & $0.41,0.54$ \\
$5: 5$ & 2.40 & 18513 & 16.4 & 17.2 & 6.48 & 550 & $0.41,0.54$ \\
$7: 3$ & 2.40 & 7033 & 13.2 & 13.8 & 4.76 & 548 & $0.41,0.54$
\end{tabular}

${ }^{a}$ Turn-on voltage at a luminance of $1 \mathrm{~cd} \mathrm{~m}^{-2} \cdot{ }^{b}$ Maximum brightness value. ${ }^{c}$ Maximum CE, current efficiency; PE, power efficiency; EQE, external quantum efficiency. ${ }^{d}$ Electroluminescence emission peak. ${ }^{e} \mathrm{CIE}$ coordinate is measured at $1000 \mathrm{~cd} \mathrm{~m}^{-2}$.

optimized molar ratio of $5: 5$. Fig. 3d shows the electroluminescence spectra of different ratios of exciplex as the emitting layer device. The emission peak position of the device with a mixing ratio of $5: 5$ is $550 \mathrm{~nm}$ at the voltage of $6 \mathrm{~V}$, which is extremely consistent with the photoluminescence peak. The energy transfer characteristics of the FSF4A:PO-T2T exciplex should be considered when it is used as the host: (1) a higher LUMO of FSF4A and a deeper HOMO of PO-T2T limit the exciton recombination zone to avoid quenching during charge transport. (2) The T1 level of FSF4A and PO-T2T is higher than the $\mathrm{T} 1$ level of the exciplex to effectively restrain the exciton energy transfer to the consisting donor or acceptor. (3) The exciplex needs to have a higher $\mathrm{T} 1$ level than phosphorescent dopants to restrain energy transfer from the phosphors to the exciplex. $^{28,29}$ According to the PL spectrum $(\mathrm{S} 1=2.258 \mathrm{eV})$ and $\Delta E_{\mathrm{st}}$ $(0.022 \mathrm{eV})$ of the exciplex, T1 can be estimated to be about $2.236 \mathrm{eV}$, which is obviously lower than FSF4A $(2.6 \mathrm{eV})$ and PO-T2T $(3.0 \mathrm{eV}){ }^{40}$ Therefore, the red dye $\operatorname{Ir}(\mathrm{MDQ})_{2}$ acac $(2.0 \mathrm{eV})$ is used as a dopant to design red PhOLEDs based on the characteristics of a novel exciplex co-host. $^{31}$

The red PhOLEDs are prepared in the structures of ITO/ $\mathrm{MoO}_{3}$ $(2 \mathrm{~nm}) / \mathrm{FSF} 4 \mathrm{~A} \quad(45 \mathrm{~nm}) / \mathrm{FSF} 4 \mathrm{~A}: \mathrm{PO}-\mathrm{T} 2 \mathrm{~T}: \quad x \quad$ wt $\% \quad \operatorname{Ir}(\mathrm{MDQ})_{2}$ acac $(20 \mathrm{~nm}) / \mathrm{PO}-\mathrm{T} 2 \mathrm{~T}(35 \mathrm{~nm}) / \mathrm{Liq}(1 \mathrm{~nm}) / \mathrm{Al}(100 \mathrm{~nm})$ and comparative device structure of ITO/MoO 3 (2 nm)/FSF4A (45 nm)/FSF4A:TPBi: $x$ wt\% $\operatorname{Ir}(\mathrm{MDQ})_{2}$ acac $(20 \mathrm{~nm}) / \mathrm{TPBi}(35 \mathrm{~nm}) / \mathrm{Liq}(1 \mathrm{~nm}) / \mathrm{Al}$ (100 nm), in which the mixing ratios of the FSF4A:PO-T2T exciplex co-host and FSF4A:TPBi common co-host are 1:1 corresponding to devices $\mathrm{A}$ and $\mathrm{B}$, and the doping concentration of the red dye $\operatorname{Ir}(\mathrm{MDQ})_{2}$ acac is $0.6 \%, 3 \%$, and $8 \%$ corresponding to devices $A_{1}-A_{3}$ and $B_{1}-B_{3}$, respectively. As can be seen from Fig. 4a, device $\mathrm{A}_{2}$ (3 $\mathrm{wt} \% \operatorname{Ir}(\mathrm{MDQ})_{2}$ acac) displays an extremely low turn-on voltage of $1.95 \mathrm{~V}$ and a maximum brightness of $35490 \mathrm{~cd} \mathrm{~m}^{-2}$. The maximum CE, PE, and EQE of $30.6 \mathrm{~cd} \mathrm{~A}^{-1}$, $38.5 \mathrm{~lm} \mathrm{~W}^{-1}$, and $17.3 \%$ are shown in Fig. $4 \mathrm{~b}$, and the inset shows the emission peak at $616 \mathrm{~nm}$ with CIE coordinates of $(0.61,0.37)$. It is encouraging that the turn-on voltage of $A_{1}-A_{3}$ is extremely low at $1.95 \mathrm{~V}$, which is even $0.05 \mathrm{~V}$ lower than the theoretical limit voltage corresponding to the emission photon energy of $\operatorname{Ir}(\mathrm{MDQ})_{2}$ acac $(2.0 \mathrm{eV})$. The extremely low turn-on voltage is due to the fact that the thermally activated carriers. ${ }^{43}$ Such low turn-on voltage and high efficiency are a great improvement compared with previous reported red OLEDs based on the exciplex co-host (Table 2). Fig. 4c shows that device $\mathrm{B}_{2}$ (with a doping concentration of $3 \mathrm{wt} \% \operatorname{Ir}(\mathrm{MDQ})_{2}$ acac) achieves a low turn-on voltage of $2.55 \mathrm{~V}$ and a maximum brightness of $24410 \mathrm{~cd} \mathrm{~m}^{-2}$. The maximum CE, PE, and EQE are $25.7 \mathrm{~cd} \mathrm{~A}^{-1}, 26.9 \mathrm{~lm} \mathrm{~W}^{-1}$, and $11.9 \%$, which can be seen in Fig. $4 \mathrm{~d}$, and the inset displays the emission peak at $612 \mathrm{~nm}$ with CIE coordinates of $(0.61,0.37)$. As can be seen, the device employing the FSF4A:PO-T2T exciplex co-host exhibits superior electroluminescence performance compared to the device employing the FSF4A:TPBi common co-host. The EL performance of device $A_{2}$ and $B_{2}$ confirms the superiority of the exciplex as co-host in achieving ultralow turn-on voltage and high efficiency, which may be attributed to the carriers being more likely to cross the barrier and the excitons being effectively transferred to the dopant. It is also noticed that the $J-V-L$ and CE-L-PE characteristics exhibited by device $A$ and $B$ with varied $\operatorname{Ir}(M D Q)_{2}$ acac
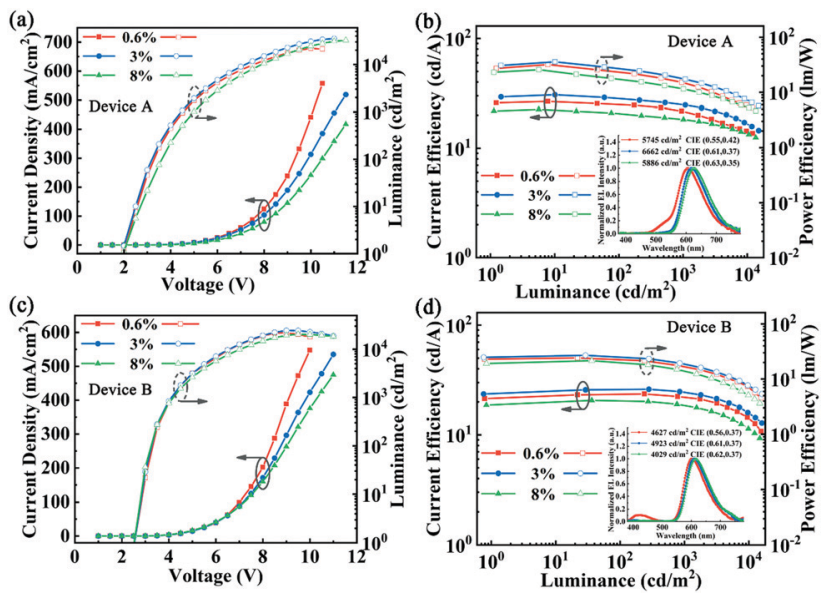

Fig. 4 (a) Current density-voltage-luminance characteristics of the device $A_{1}-A_{3}$. (b) Current efficiency-luminance-power efficiency characteristics of the device $A_{1}-A_{3}$, inset shows normalized EL spectra of the devices at $6 \mathrm{~V}$. (c) Current density-voltage-luminance characteristics of the device $B_{1}-B_{3}$. (d) Current efficiency-luminance-power efficiency characteristics of the device $B_{1}-B_{3}$, inset shows normalized EL spectra of the devices at $6 \mathrm{~V}$. 
Table 2 Summary of EL performance of red OLEDs based on the exciplex co-host

\begin{tabular}{llllll}
\hline & & $\begin{array}{l}L_{\max }{ }^{b} \\
{\left[\mathrm{~cd} \mathrm{~m}^{-2}\right]}\end{array}$ & $\begin{array}{l}\mathrm{CE}_{\max }{ }^{c}[\mathrm{~V}] \\
{\left[\mathrm{cd} \mathrm{A}^{-1}\right]}\end{array}$ & $\begin{array}{l}\mathrm{PE}_{\max }{ }^{d} \\
{\left[\mathrm{~lm} \mathrm{~W}^{-1}\right]}\end{array}$ & $\begin{array}{l}\mathrm{EQE}_{\max }{ }^{e} \\
{[\%]}\end{array}$ \\
\hline This work & 1.95 & 35490 & 30.6 & 38.5 & 17.3 \\
30 & 2.4 & 26385 & 31.1 & 36.9 & 15.5 \\
41 & 2.35 & 7694 & 34.0 & 44.3 & 19.2 \\
31 & 1.90 & - & - & 48.9 & 26.8 \\
29 & 2.24 & - & 32.87 & 31.80 & 11.01 \\
42 & 2.4 & - & 36.0 & 46.1 & 24.5 \\
38 & 2.0 & - & 30.13 & 42.75 & 16.07 \\
28 & 2.6 & 33560 & 33.9 & 35.3 & 19.8
\end{tabular}

${ }^{a}$ Turn-on voltage at a luminance of $1 \mathrm{~cd} \mathrm{~m}^{-2} \cdot{ }^{b}$ Maximum brightness value. ${ }^{c}$ Maximum CE, current efficiency. ${ }^{d}$ Maximum PE, power efficiency. ${ }^{e}$ Maximum EQE, external quantum efficiency.

doping concentrations are quite different, as shown in Fig. 4. Detailed characteristics for device $A_{1}-A_{3}$ and $B_{1}-B_{3}$ are summarized in Table 3.

It can be seen from the insets that the host emission peaks exist only at a low doping concentration of $0.6 \% \operatorname{Ir}(\mathrm{MDQ})_{2}$ acac, which can be explained as an incomplete energy transfer from the host to the dopant. The EL efficiency declined as the doping concentration of $\operatorname{Ir}(\mathrm{MDQ})_{2}$ acac increases to $8 \%$, which is due to the strengthening of triplet-triplet annihilation, and triplet-polaron quenching with a higher proportion of dye. Meanwhile, a slight red shift with increasing doping concentration can be observed in the insets of Fig. 4(b and d), which is due to reabsorption of the emitter emission. Based on the above results, it is confirmed that the FSF4A:PO-T2T exciplex co-host doped with 3\% $\operatorname{Ir}(\mathrm{MDQ})_{2}$ acac concentration achieves the optimal EL efficiency.

To further understand the effect of dopant on the charge transport properties of the device, we subsequently research the charge transport properties by varying the doping concentration of hole-only and electron-only devices with the structures of ITO/ $\mathrm{MoO}_{3}(2 \mathrm{~nm}) / \mathrm{FSF} 4 \mathrm{~A}(45 \mathrm{~nm}) / \mathrm{FSF} 4 \mathrm{~A}: \mathrm{PO}-\mathrm{T} 2 \mathrm{~T}: x \mathrm{wt} \% \operatorname{Ir}(\mathrm{MDQ})_{2}$ acac $(20 \mathrm{~nm}) / \mathrm{FSF} 4 \mathrm{~A}(35 \mathrm{~nm}) / \mathrm{MoO}_{3}(1 \mathrm{~nm}) / \mathrm{Al}$ and ITO/Liq $(1 \mathrm{~nm}) /$ PO-T2T (45 nm)/FSF4A:PO-T2T: $x$ wt\% $\operatorname{Ir}(\text { MDQ })_{2}$ acac $(20 \mathrm{~nm}) /$ PO-T2T $(35 \mathrm{~nm}) / \mathrm{Liq}(1 \mathrm{~nm}) / \mathrm{Al}$, respectively. Here $x$ is $0,0.6,3$, and 8. Fig. 5 exhibits the current density-voltage characteristics of these devices. Obviously we can notice that the charge carrier transmission of the device tends to be more balanced as the doping concentration of $\operatorname{Ir}(\mathrm{MDQ})_{2}$ acac is increased from $0 \%$ to $8 \%$, it is due to the fact that $\operatorname{Ir}(\mathrm{MDQ})_{2}$ acac has a strong hole trap effect and creates an additional electron transport channel. $\operatorname{Ir}(\mathrm{MDQ})_{2} \mathrm{acac}$
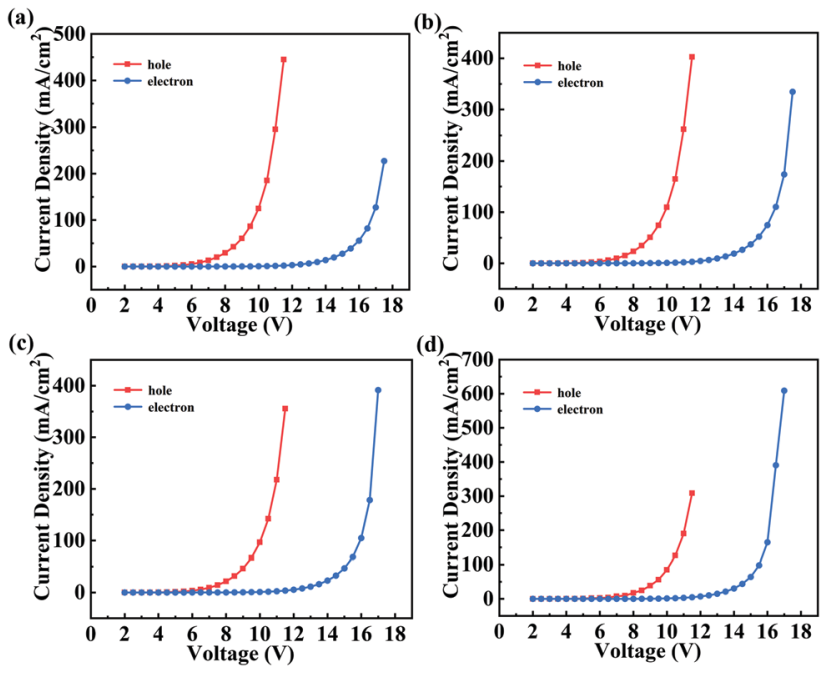

Fig. 5 The current density-voltage characteristics of (a) $0 \% \operatorname{Ir}(\mathrm{MDQ})_{2} \mathrm{acac}$, (b) $0.6 \% \operatorname{Ir}(M D Q)_{2} a c a c$, (c) $3 \% \operatorname{Ir}(M D Q)_{2}$ acac, and (d) $8 \% \operatorname{Ir}(M D Q)_{2} a c a c$.

has the highest occupied molecular orbital energy level of $5.1 \mathrm{eV}$, which is a $0.2 \mathrm{eV}$ difference to that of FSF4A $(5.3 \mathrm{eV})$, indicating that $\operatorname{Ir}(\mathrm{MDQ})_{2}$ acac acts as trapping sites for holes. On the contrary, the current density of electron-only devices increases with increasing the doping concentration of $\operatorname{Ir}(\mathrm{MDQ})_{2}$ acac. The improvement can be attributed to the fact the $\operatorname{Ir}(\mathrm{MDQ})_{2}$ acac molecules create an additional electron transport channel, which is beneficial for more balanced charge carriers in the devices. Overall, it is found that doping $\operatorname{Ir}(\mathrm{MDQ})_{2}$ acac into an exciplex co-host can simultaneously trap holes and facilitate electron transport. Both of these processes lead to more balanced charge carriers, which causes a slight shift of the recombination zone to the center of the device. ${ }^{44}$

The energy transfer mechanism of red OLEDs based on the exciplex co-host is illustrated in Fig. 6. Excitons are produced by the direct recombination between holes on the donor (FSF4A) and electrons on the acceptor (PO-T2T), the exciplex excitons can also be divided into singlet excitons of $25 \%$ and triplet excitons of $75 \%$. For singlet excitons of the exciplex, one is converted to triplet excitons by intersystem crossing, and the other is to transfer energy to the dopant by Förster energy transfer (FRET); for triplet excitons of the exciplex, part of which can diffuse into the dopant through Dexter energy transfer (DET), but the triplet energy is lost as the diffusion length increases. ${ }^{45}$ Meanwhile, another triplet could upconvert

Table 3 The EL performance summary of the red PhOLEDs

\begin{tabular}{|c|c|c|c|c|c|c|}
\hline Device & Doping concentration $^{a}(\%)$ & $V_{\mathrm{on}}{ }^{b}[\mathrm{~V}]$ & $\mathrm{CE}_{\max / 1000 / 3000}{ }^{c}\left[\mathrm{~cd} \mathrm{~A}^{-1}\right]$ & $\mathrm{PE}_{\max / 1000 / 3000}{ }^{d}\left[\operatorname{lm~W^{-1}]}\right.$ & $\mathrm{EQE}_{\max / 1000 / 3000}{ }^{e}[\%]$ & $\operatorname{CIE}^{f}[x, y]$ \\
\hline $\mathrm{A}_{1}$ & 0.6 & 1.95 & 26.6/23.3/18.3 & $33.4 / 18.0 / 10.3$ & 15.2/11.1/9.6 & $(0.56,0.42)$ \\
\hline $\mathrm{A}_{2}$ & 3 & 1.95 & $30.6 / 26.0 / 21.7$ & $38.5 / 20.4 / 12.4$ & $17.3 / 12.8 / 10.4$ & $(0.61,0.37)$ \\
\hline$A_{3}$ & 8 & 1.95 & $22.6 / 18.9 / 16.6$ & 28.4/13.2/8.7 & $13.8 / 7.9 / 5.9$ & $(0.64,0.35)$ \\
\hline $\mathrm{B}_{1}$ & 0.6 & 2.55 & 23.1/21.1/17.7 & $24.2 / 14.7 / 10.1$ & $10.7 / 8.4 / 6.5$ & $(0.57,0.37)$ \\
\hline $\mathrm{B}_{2}$ & 3 & 2.55 & $25.7 / 24.7 / 19.5$ & 26.9/19.4/11.1 & $11.9 / 10.7 / 8.2$ & $(0.61,0.37)$ \\
\hline $\mathrm{B}_{3}$ & 8 & 2.55 & $20.6 / 17.6 / 15.0$ & 21.5/12.3/8.6 & $9.6 / 7.6 / 5.7$ & $(0.62,0.36)$ \\
\hline
\end{tabular}

${ }^{a}$ Doping concentration of $\operatorname{Ir}(\mathrm{MDQ})_{2}$ acac. ${ }^{b}$ Turn-on voltage at a luminance of $1 \mathrm{~cd} \mathrm{~m}^{-2}{ }^{c}$ The maximum current efficiency/current efficiency at $1000 \mathrm{~cd} \mathrm{~m}^{-2} /$ current efficiency at $3000 \mathrm{~cd} \mathrm{~m}^{-2}$. $^{d}$ The maximum power efficiency/power efficiency at $1000 \mathrm{~cd} \mathrm{~m} \mathrm{~m}^{-2} /$ power efficiency at $3000 \mathrm{~cd} \mathrm{~m} \mathrm{~m}^{-2}$. ${ }^{e}$ The maximum EQE/EQE at $1000 \mathrm{~cd} \mathrm{~m}^{-2} / \mathrm{EQE}$ at $3000 \mathrm{~cd} \mathrm{~m}^{-2} .{ }^{f} \mathrm{CIE}$ coordinates are measured at $1000 \mathrm{~cd} \mathrm{~m}^{-2}$. 


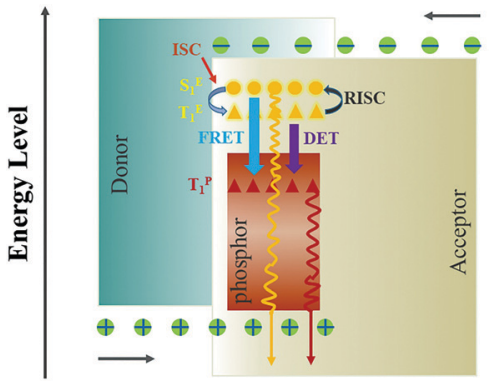

Fig. 6 Operational mechanism of the exciplex type host

into the singlet by the reverse intersystem crossing due to the small $\Delta E_{\mathrm{st}}$ of the exciplex. This process can effectively reduce energy loss due to improving FRET energy transfer and suppressing DET energy transfer. Therefore, we can achieve efficient and stable exciplex co-host PhOLEDs.

Based on the above excellent monochrome devices, ultra-thin blue layers and spacer-layers are inserted to achieve highperformance WOLEDs, and the device structure is $\mathrm{ITO} / \mathrm{MoO}_{3}$ $\left(\begin{array}{ll}2 & \mathrm{~nm}\end{array}\right) / \mathrm{FSF} 4 \mathrm{~A} \quad(45 \mathrm{~nm}) / \mathrm{FSF} 4 \mathrm{~A}: \mathrm{PO}-\mathrm{T} 2 \mathrm{~T}: \quad 3 \quad \mathrm{wt} \% \quad \operatorname{Ir}(\mathrm{MDQ})_{2}$ acac $(20 \mathrm{~nm}) / \mathrm{MCP}(x \mathrm{~nm}) / \mathrm{FIrPic}(0.2 \mathrm{~nm}) / \mathrm{PO}-\mathrm{T} 2 \mathrm{~T}(35 \mathrm{~nm}) / \mathrm{Liq}(1 \mathrm{~nm}) / \mathrm{Al}$ $(100 \mathrm{~nm})$, as shown in Fig. 7a. The $x$ is 1, 2, 3 and 4, corresponding to devices $\mathrm{W}_{1}, \mathrm{~W}_{2}, \mathrm{~W}_{3}$ and $\mathrm{W}_{4}$, respectively. As can be seen from Fig. $7 \mathrm{~b}$, all WOLEDs realize an ultra-low turn-on voltage of $2.20 \mathrm{~V}$ due to the barrier-free charge transfer. The current density of the four devices decreases as the thickness of the spacer layer increases, which can be explained by the following formula ( $J-V$ curves) $:^{52}$

$$
J \propto \mu \frac{v^{m+1}}{d^{2 m+1}}
$$

where $\mu$ and $d$ correspond to the carrier mobility and the thickness of the device, $m$ is defined as $m=E_{\text {trap }} / K T\left(E_{\text {trap }}\right.$ is characteristic energy of the trap distribution, $k$ is the Boltzmann constant, and $T$ is the device operating temperature). Meanwhile,
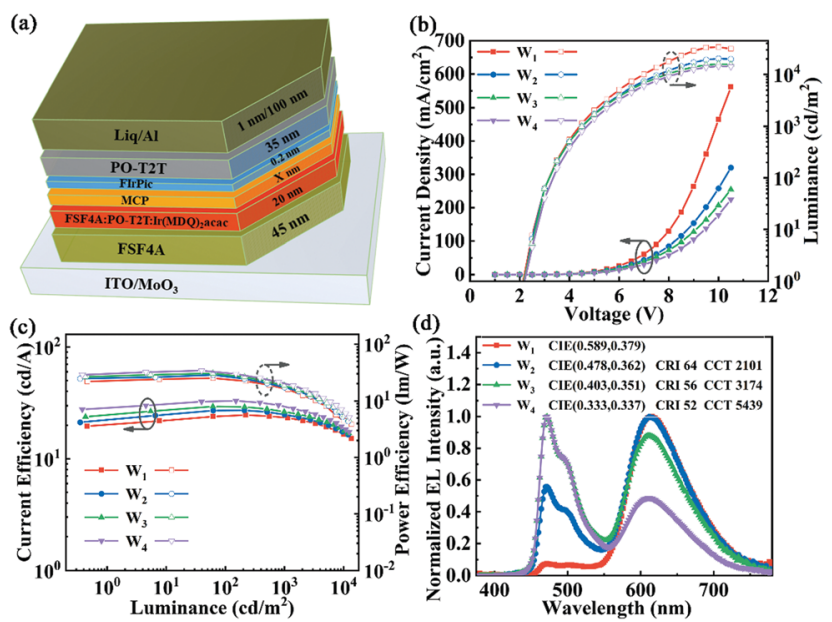

(d)

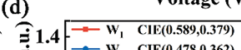

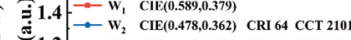
$\begin{array}{llll}1.2 & -1-w_{3} & C I E(0.403,0.351) & \text { CRI } 56 \text { CCT } 3174 \\ 1.0-w_{4} & \text { CIE( }(0.333,0.337) & \text { CRI } 52 \text { CCT } 5439\end{array}$

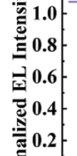
0.4 0.0

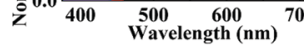

Fig. 7 (a) The structures of the white OLEDs. (b) The current densityvoltage-luminance characteristics of devices $W_{1}-W_{4}$. (c) The current efficiency-luminance-power efficiency characteristics of devices $W_{1}-W_{4}$. (d) Normalized EL spectra of the devices $W_{1}-W_{4}$ at $5 \mathrm{~V}$. the EL efficiency of the four devices has a significant improvement as the thickness of the spacer layer increases. As depicted in Fig. 7c, the maximum CE of $32.6 \mathrm{~cd} \mathrm{~A}^{-1}$ and PE of $34.1 \mathrm{~lm} \mathrm{~W}^{-1}$, corresponding to an external quantum efficiency of $12.4 \%$, are achieved in the $\mathrm{W}_{4}$. Such a low turn-on voltage and high efficiency when the standard CIE coordinate of $(0.33,0.33)$ is achieved at a luminance of $1000 \mathrm{~cd} \mathrm{~m}^{-2}$ are a great enhancement compared to previously reported WOLEDs (Table 4). The low CE roll-off is clearly observed in devices $\mathrm{W}_{1}-\mathrm{W}_{4}$, for device $\mathrm{W}_{4}$, the current efficiency drops to $30.3 \mathrm{~cd} \mathrm{~A}^{-1}$ at $1000 \mathrm{~cd} \mathrm{~m}^{-2}$, corresponding to the roll-off of $7.1 \%$. The low efficiency roll-off could be attributed to the extended exciton recombination zone due to balanced carrier transport. Meanwhile, according to the reported reference, there is an interface exciplex between the interlayer MCP and the electron transport layer PO-T2T, and the emission peak position of the exciplex is about $452 \mathrm{~nm}(2.74 \mathrm{eV}){ }^{53}$ The FIrPic emission peak position is about $476 \mathrm{~nm}(2.6 \mathrm{eV})$. Therefore, we believe that there is energy transfer from the interface exciplex to phosphorescent dyes, which can improve the efficiency of the devices. Detailed characteristics of the $\mathrm{W}_{1}-\mathrm{W}_{4}$ are summarized in Table 5. As shown in Fig. $7 d$, device $\mathrm{W}_{1}$ shows an intense red emission peak and quite weak blue emission, which is the result of energy transfer from the blue emission layer to the red emission layer caused by the thinner spacer layer. The blue emission gradually increases as the thickness of the spacer MCP increases. Device $\mathrm{W}_{4}$ achieves a WOLED with CIE coordinates of $(0.33,0.33)$ at $1000 \mathrm{~cd} \mathrm{~m}^{-2}$, corresponding to the CRI of 52 and CCT of 5439.

Fig. 8 exhibits the normalized EL spectra of devices $W_{1}-W_{4}$ at different luminance. The device $\mathrm{W}_{1}$ shows a rather weak blue emission, which can be attributed to the strong energy transfer due to the thinner spacer layer. Obviously, for white devices $\mathrm{W}_{2}$, $\mathrm{W}_{3}$, and $\mathrm{W}_{4}$, the relatively stable spectra are displayed in a large luminance range with a slight CIE coordinate shift. The CIE coordinate shift of device $\mathrm{W}_{2}-\mathrm{W}_{4}$ is from $(0.488,0.366)$, $(0.414,0.353)$, and $(0.352,0.343)$ at $4 \mathrm{~V}$ to $(0.462,0.362)$, $(0.386,0.350)$, and $(0.326,0.340)$ at $7 \mathrm{~V}$, revealing the CIE variation is only $(0.026,0.004),(0.028,0.003)$, and $(0.026,0.003)$, respectively. The only slight colour shift in the EL spectra may be attributed to the bipolarity of the exciplex co-host, which reduces the recombination zone movement. Meanwhile, as the thickness

Table 4 Summary of EL performance of white OLEDs

\begin{tabular}{llllllll}
\hline & $\begin{array}{l}V_{\text {on }}{ }^{a} \\
{[\mathrm{~V}]}\end{array}$ & $\begin{array}{l}L^{b} \\
{\left[\mathrm{~cd} \mathrm{~m}^{-2}\right]}\end{array}$ & $\begin{array}{l}\mathrm{CE}^{c} \\
{\left[\mathrm{~cd} \mathrm{~A}^{-1}\right]}\end{array}$ & $\begin{array}{l}\mathrm{PE}^{c} \\
{\left[\mathrm{~lm} \mathrm{~W}^{-1}\right]}\end{array}$ & $\begin{array}{l}\mathrm{EQE}^{c} \\
{[\%]}\end{array}$ & $\begin{array}{l}\mathrm{CIE}^{d} \\
{[x, y]}\end{array}$ & CRI \\
\hline This & 2.20 & 14420 & 32.6 & 34.1 & 12.4 & $(0.33,0.33)$ & 52 \\
work & & & & & & & \\
46 & 4.43 & - & 28.0 & 20.2 & 12.0 & $(0.33,0.33)$ & 83 \\
47 & - & - & 23.1 & 15.6 & 13.5 & $(0.33,0.34)$ & 59 \\
48 & 3.20 & 19200 & 10.7 & 8.1 & 6.4 & $(0.33 .0 .33)$ & - \\
49 & 2.62 & - & 44.0 & 52.7 & 19.0 & $(0.34,0.35)$ & 72.2 \\
24 & 3.0 & - & 36.50 & 37.31 & 13.39 & $(0.35,0.39)$ & 78 \\
50 & - & - & 27.2 & 21.4 & 11.2 & $(0.35 .0 .39)$ & 66 \\
51 & 2.5 & - & 36.7 & 46.2 & 19.2 & $(0.33,0.38)$ & 82
\end{tabular}

${ }^{a}$ Turn-on voltage at a luminance of $1 \mathrm{~cd} \mathrm{~m}^{-2} \cdot{ }^{b}$ Maximum brightness value. ${ }^{c}$ Maximum CE, PE, and EQE. ${ }^{d}$ The CIE coordinates at $1000 \mathrm{~cd} \mathrm{~m}^{-2}$. 
Table 5 The EL performance summary of white OLEDs

\begin{tabular}{|c|c|c|c|c|c|c|c|}
\hline Device & $V_{\text {on }}[\mathrm{V}]$ & $\mathrm{CE}\left[\mathrm{cd} \mathrm{A}^{-1}\right]_{\max / 1000 / 3000}$ & $\operatorname{PE}\left[\operatorname{lm~W}{ }^{-1}\right]_{\max / 1000 / 3000}$ & $\mathrm{EQE}[\%]_{\max / 1000 / 3000}$ & Roll-off $^{a}(\%)$ & $\operatorname{CIE}^{b}[x, y]$ & $\Delta \operatorname{CIE}^{c}[x, y]$ \\
\hline $\mathrm{W}_{2}$ & 2.20 & $27.1 / 24.9 / 22.5$ & 28.5/17.2/12.1 & $11.0 / 9.8 / 8.4$ & 8.1 & $(0.478,0.362)$ & $(0.026,0.004)$ \\
\hline
\end{tabular}

${ }^{a}$ The CE roll-off at $1000 \mathrm{~cd} \mathrm{~m}^{-2} \cdot{ }^{b}$ The CIE coordinates at $1000 \mathrm{~cd} \mathrm{~m}^{-2} \cdot{ }^{c}$ The CIE coordinate variation from 4 to $7 \mathrm{~V}$.
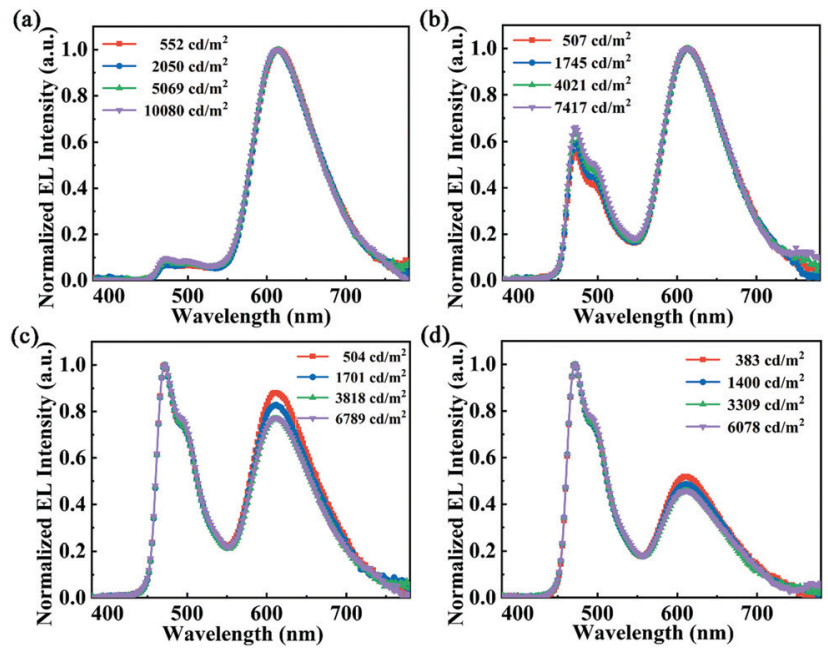

Fig. 8 Normalized EL spectra of the devices $W_{1}-W_{4}$ at different luminance.

of the spacer layer increases, the colour rending index of devices $\mathrm{W}_{2}-\mathrm{W}_{4}$ sequentially decreases, which is due to the gradual decrease of the red emission peak.

\section{Conclusions}

In summary, we have successfully achieved ultralow turn-on voltage, high-performance simplified red and white phosphorescent OLEDs based on a novel exciplex co-host. The energy transfer from the exciplex co-host to its constituents is completely suppressed due to the high $\mathrm{E}_{\mathbf{T}}$ of both FSF4A and PO-T2T, while from the host to the dopant is improved through long-range Förster energy transfer. The red device implements an ultra-low turn-on voltage of $1.95 \mathrm{~V}$ and the maximum EQE of $17.3 \%$ under a low doping level of $3 \mathrm{wt} \%$, which is due to barrier-free charge transfer and effective energy transfer. Meanwhile, white OLEDs with a low turn-on voltage of $2.2 \mathrm{~V}$ is realized based on doping red dye and inserting an ultra-thin blue layer, the optimized device shows relatively stable spectra and low efficiency roll-off. These superior performances can be attributed to the balanced charge transfer of the exciplex co-host and the effective energy transfer from the exciplex co-host to the dopant. Such results indicate a promising method for designing simplified highperformance OLEDs.

\section{Conflicts of interest}

There are no conflicts to declare.

\section{Acknowledgements}

The work was funded by the Project of Science and Technology Development Plan of Jilin Province (20190302011GX) and the National Natural Science Foundation of China (61675088 and 61675089).

\section{References}

1 X. Cai, R. Liu, H. Shi, C. Li and H. Zhu, Dyes Pigm., 2017, 143, 196-202.

2 K. Gao, K. Liu, X.-L. Li, X. Cai, D. Chen, Z. Xu, Z. He, B. Li, Z. Qiao, D. Chen, Y. Cao and S.-J. Su, J. Mater. Chem. C, 2017, 5(39), 10406-10416.

3 C. Adachi, R. C. Kwong, P. Djurovich, V. Adamovich, M. A. Baldo, M. E. Thompson and S. R. Forrest, Appl. Phys. Lett., 2001, 79(13), 2082-2084.

4 Y. J. Cho, K. S. Yook and J. Y. Lee, Sci. Rep., 2015, 5, 7859.

5 N. Sun, Q. Wang, Y. Zhao, Y. Chen, D. Yang, F. Zhao, J. Chen and D. Ma, Adv. Mater., 2014, 26(10), 1617-1621.

6 B. Q. Liu, L. Wang, D. Y. Gao, J. H. Zou, H. L. Ning, J. B. Peng and Y. Cao, Light: Sci. Appl., 2016, 5(8), e16137.

7 L. Jia, L. Jin, K. Yuan, L. Chen, J. Yuan, S. Xu, W. Lv and R. Chen, ACS Sustainable Chem. Eng., 2018, 6(7), 8809-8815.

8 P. Chen, R. Sheng, M.-Y. Ko, Y. Duan, G. Cheng and C.-M. Che, J. Mater. Chem. C, 2018, 6(37), 9890-9896.

9 S. Ying, J. Yao, Y. Chen and D. Ma, J. Mater. Chem. C, 2018, 6(26), 7070-7076.

10 X. Liao, K. An, J. Cheng, Y. Li, X. Meng, X. Yang and L. Li, Appl. Surf. Sci., 2019, 487, 610-615.

11 J. Zhao, S. Yuan, X. Du, W. Li, C. Zheng, S. Tao and X. Zhang, Adv. Opt. Mater., 2018, 6(23), 1800825.

12 R. J. Holmes, S. R. Forrest, Y. J. Tung, R. C. Kwong, J. J. Brown, S. Garon and M. E. Thompson, Appl. Phys. Lett., 2003, 82(15), 2422-2424.

13 M.-S. Lin, S.-J. Yang, H.-W. Chang, Y.-H. Huang, Y.-T. Tsai, C.-C. Wu, S.-H. Chou, E. Mondal and K.-T. Wong, J. Mater. Chem., 2012, 22(31), 16114-16120.

$14 \mathrm{H} . \mathrm{Mu}, \mathrm{Y}$. Jiang and H. Xie, Org. Electron., 2019, 66, 195-205.

15 Z. Wang, C. Wang, H. Zhang, Z. Liu, B. Zhao and W. Li, Org. Electron., 2019, 66, 227-241. 
16 H.-Y. Yang, C.-J. Zheng, M. Zhang, J.-W. Zhao, P.-L. Zhong, H. Lin, S.-L. Tao and X.-H. Zhang, Org. Electron., 2019, 73, 36-42.

17 W. Zeng, T. Zhou, W. Ning, C. Zhong, J. He, S. Gong, G. Xie and C. Yang, Adv. Mater., 2019, 31(33), e1901404.

18 S. Yuan, X. Du, J. Zhao, W. Liu, H. Lin, C. Zheng, S. Tao and X. Zhang, Org. Electron., 2016, 39, 10-15.

19 P. Chen, B. Chen, L. Zuo, Y. Duan, G. Han, R. Sheng, K. Xue and Y. Zhao, Org. Electron., 2016, 31, 136-141.

20 T.-C. Liao, H.-T. Chou, F.-S. Juang, Y.-S. Tsai, L.-A. Hong and Y.-Y. Ho, Curr. Appl. Phys., 2013, 13, S152-S155.

21 K.-H. Kim, S.-J. Yoo and J.-J. Kim, Chem. Mater., 2016, 28(6), 1936-1941.

22 C. J. Zheng, J. Wang, J. Ye, M. F. Lo, X. K. Liu, M. K. Fung, X. H. Zhang and C. S. Lee, Adv. Mater., 2013, 25(15), 2205-2211.

23 P. Yuan, X. Qiao, D. Yan and D. Ma, J. Mater. Chem. C, 2018, 6(21), 5721-5726.

24 Y. Liu, X. Wei, Z. Li, J. Liu, R. Wang, X. Hu, P. Wang, T. Qi and Y. Wang, Adv. Opt. Mater., 2018, 6(23), 1800978.

25 F. Yan, R. Chen, H. Sun and X. Wei Sun, Appl. Phys. Lett., 2014, 104(15), 153302.

26 Y. Seino, H. Sasabe, Y. J. Pu and J. Kido, Adv. Mater., 2014, 26(10), 1612-1616.

27 B. Zhao, Y. Miao, Z. Wang, W. Chen, K. Wang, H. Wang, Y. Hao, B. Xu and W. Li, Org. Electron., 2016, 37, 1-5.

28 R. Sheng, A. Li, F. Zhang, J. Song, Y. Duan and P. Chen, Adv. Opt. Mater., 2020, 8(2), 1901247.

29 T. Xu, Y. X. Zhang, B. Wang, C. C. Huang, I. Murtaza, H. Meng and L. S. Liao, ACS Appl. Mater. Interfaces, 2017, 9(3), 2701-2710.

30 B. Yao, X. Lin, B. Zhang, H. Wang, X. Liu and Z. Xie, J. Mater. Chem. C, 2018, 6(16), 4409-4417.

31 J. H. Lee, H. Shin, J. M. Kim, K. H. Kim and J. J. Kim, ACS Appl. Mater. Interfaces, 2017, 9(4), 3277-3281.

32 Y.-L. Zhang, Q. Ran, Q. Wang, J. Fan and L.-S. Liao, J. Mater. Chem. C, 2019, 7(24), 7267-7272.

33 X. Tang, X. Y. Liu, Y. Yuan, Y. J. Wang, H. C. Li, Z. Q. Jiang and L. S. Liao, ACS Appl. Mater. Interfaces, 2018, 10(35), 29840-29847.

34 D. Chen, Z. Wang, D. Wang, Y.-C. Wu, C.-C. Lo, A. Lien, Y. Cao and S.-J. Su, Org. Electron., 2015, 25, 79-84.

35 S.-F. Wu, S.-H. Li, Y.-K. Wang, C.-C. Huang, Q. Sun, J.-J. Liang, L.-S. Liao and M.-K. Fung, Adv. Funct. Mater., 2017, $27(31), 1701314$.
36 X. K. Liu, Z. Chen, C. J. Zheng, C. L. Liu, C. S. Lee, F. Li, X. M. Ou and X. H. Zhang, Adv. Mater., 2015, 27(14), 2378-2383.

37 X. K. Liu, Z. Chen, J. Qing, W. J. Zhang, B. Wu, H. L. Tam, F. Zhu, X. H. Zhang and C. S. Lee, Adv. Mater., 2015, 27(44), 7079-7085.

38 X. Liao, K. An, Y. Li, X. Meng, S. Chen, X. Yang and L. Li, Dyes Pigm., 2020, 182.

39 J.-H. Lee, S.-H. Cheng, S.-J. Yoo, H. Shin, J.-H. Chang, C.-I. Wu, K.-T. Wong and J.-J. Kim, Adv. Funct. Mater., 2015, 25(3), 361-366.

40 M. Colella, A. Danos and A. P. Monkman, J. Phys. Chem. C, 2019, 123(28), 17318-17324.

41 J. Zhao, X. Du, S. Yuan, C. Zheng, H. Lin and S. Tao, Org. Electron., 2017, 43, 136-141.

42 Q.-S. Tian, X.-D. Zhu and L.-S. Liao, Mater. Chem. Front., 2020, 4(6), 1648-1655.

43 H. Sasabe, H. Nakanishi, Y. Watanabe, S. Yano, M. Hirasawa, Y.-J. Pu and J. Kido, Adv. Funct. Mater., 2013, 23(44), 5550-5555.

44 Y. Chen, Y. Xia, G. M. Smith, C. A. Hewitt, Q. Fu, Y. Liu, H. Sun, D. Ma, Y. Gu, C. Yang, Y. Mei and D. L. Carroll, Org. Electron., 2014, 15(1), 182-188.

45 D. Zhang, M. Cai, Y. Zhang, D. Zhang and L. Duan, ACS Appl. Mater. Interfaces, 2015, 7(51), 28693-28700.

46 W. Luo, T.-T. Wang, X. Chen, K.-N. Tong, W. He, S.-Q. Sun, Y.-J. Zhang, L.-S. Liao and M.-K. Fung, J. Mater. Chem. C, 2020, 8(30), 10431-10437.

47 C.-C. Fan, M.-H. Huang, W.-C. Lin, H.-W. Lin, Y. Chi, H.-F. Meng, T.-C. Chao and M.-R. Tseng, Org. Electron., 2014, 15(2), 517-523.

48 W. Qin, Z. Yang, Y. Jiang, J. W. Y. Lam, G. Liang, H. S. Kwok and B. Z. Tang, Chem. Mater., 2015, 27(11), 3892-3901.

49 H. Sasabe, J. Takamatsu, T. Motoyama, S. Watanabe, G. Wagenblast, N. Langer, O. Molt, E. Fuchs, C. Lennartz and J. Kido, Adv. Mater., 2010, 22(44), 5003-5007.

50 D. Feng, D. Dong, L. Lian, H. Wang and G. He, Org. Electron., 2018, 56, 216-220.

51 M. Zhang, K. Wang, C.-J. Zheng, W. Liu, H. Lin, S.-L. Tao and X.-H. Zhang, Org. Electron., 2017, 50, 466-472.

52 B. Wang, Z. Kou, Y. Tang, F. Yang, X. E. Fu and Q. Yuan, Org. Electron., 2019, 70, 149-154.

53 H. Wang, D. Dong, L. Lian, F. Zhu, D. Xu, S. Wu and G. He, Phys. Status Solidi A, 2019, 216(11), 1900034. 